\title{
The Learning Process: A Tourist Visitor to the National Museum
}

\author{
Issarapong Poltanee \\ Khon Kaen University, Khon Kaen, Thailand \\ Kasetsart University, Kamphaeng Saen, Thailand \\ Noppamash Suvachart \\ Khon Kaen University, Khon Kaen, Thailand
}

\begin{abstract}
This paper aims to develop an understanding of the undergraduate students’ learning by applying Kolb’s (1984) learning concepts and theories. This research aims: (1) to study the visitors' learning experience; (2) to compare the learning process of visitors; and (3) to design learning process development for the visitors of the Phra Pathom Chedi National Museum. The quantitative methodology was used for data collection. The population was focused on group samplings of 300 participants and the selection method was a non-probability and purposive sampling. The research instrument was the structured questionnaire. Descriptive statistics, $T$-test, $F$-test (one-way analysis of variance (ANOVA)), and regression analysis were used for data analysis. According to the first objective, the study revealed that most of visitors were female, at the age of 19 years old, had a bachelor degree, and had income less than 5,000 baht. Their learning levels at the Phra Pathom Chedi National Museum were high. According to the second objective, the study found that there was no correlation between gender and income to the visitors' learning process related to the theoretical four learning processes which are: (1) before learning; (2) learning behavior; (3) while learning; and (4) the best ways of learning that create the most understanding. However, age and education varied the level of visitors' learning process. According to the third objective regarding the four models of learning process development design, the study presented that: (1) For the accommodators, the visitors should be male, at a young age, and have a bachelor degree; (2) For the divergers, the visitors should be at a young age and have a bachelor degree; (3) For the convergers, the visitors should be at a young age, have a bachelor degree, and not with high income; and (4) For the assimilators, the visitors should be at a young age, have a bachelor degree, and with high income.
\end{abstract}

Keywords: learning process, national museum, Phra Pathom Chedi

\section{Introduction}

This research studies the learning process of visitors to the Phra Pathom Chedi National Museum. For this study, undergraduate students are assumed to be the key age group that can create knowledge from learning (Pavlov, 1927). The aim is to develop an understanding of the learning process for a group of students using Kolb's (1984) concepts and theories of learning styles. The results could then be used to promote the development of learning behavior (Skinner, 1938) necessary for effective learning in museums. In order to do

Issarapong Poltanee, Ph.D. candidate, Tourism and Hospitality Management, Khon Kaen University; lecturer, Department of Service Industry and Language Innovation, Faculty of Arts and Science, Kamphaeng Saen Campus, Kasetsart University. Email: issarapong_aaa@hotmail.com.

Noppamash Suvachart, associate professor, DBA, Faculty of Management Sciences, Khon Kaen University. 
this, it was important to gain an accurate understanding of the learning process of the visitors to the museum with a focus on undergraduate students. The results of the survey indicate that there is still a lack of knowledge of accurate learning with respect to this tourist attraction and especially with regard to the undergraduate students who visit the museum. This study of the learning processes of different kinds of museum visitors would therefore benefit the museum by providing information which could help to make the museum more interesting for visitors and especially for the undergraduate target group.

\section{Aim of the Research Study}

This research aims: (1) to study the visitors' learning experience; (2) to compare the learning process of visitors; and (3) to design learning process development for the visitors of the Phra Pathom Chedi National Museum.

\section{Identifying the Problems}

For the study purpose, we provide the following research problems:

(1) What are the learning styles of tourists who visit the Phra Pathom Chedi National Museum?

(2) What are the results of the multiple linear regression analysis with respect to the learning process of visitors to the Phra Pathom Chedi National Museum?

\section{Related Works}

The theoretical literature supporting these research findings is as follows.

\section{Learning Style Theory}

Visitors to the Phra Pathom Chedi National Museum encounter a variety of learning experiences at every level. They learn new things during their visits and these experiences are relevant to each stage of the learning cycle and support the learning process as well. Learning in the museum uses Kolb's learning cycle theory (see Figure 1), which aims to provide museum visitors with knowledge and understanding of other national museums; the model employed could also be used as a set of guidelines that provide opportunities for students to gain the experience of learning in the national museum visit and in so doing allow them to search for and build their understandings from a test that is based on Kolb's (1985) model. It includes four aspects of learning:

(1) Feeling: learning through senses and emotions;

(2) Observing: learning things through observation and summarization;

(3) Thinking: learning through rational feedback;

(4) Doing: learning through practice, e.g., a visit to the Phra Pathom Chedi National Museum.

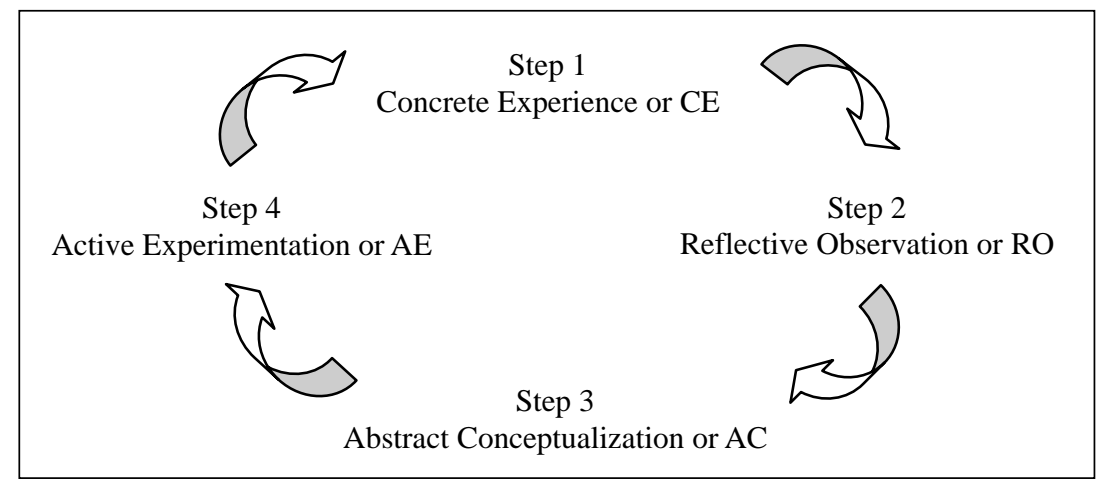

Figure 1. Kolb’s cycle of the experiential learning process. 
Kolb's theory suggests that an educational museum has different learning styles (see Figure 2) of information, which require various learning methods. These include: (1) learning by feelings; (2) learning by observation; (3) learning by thinking; and (4) learning by doing. Given these different learning methods, visitors can be sorted into four categories of learning styles according to Kolb.

The accommodator: learning by doing and feeling. People with this learning style usually learn through "hands-on" experience. They enjoy carrying out plans and involving themselves in new and challenging experiences. Their tendency is to act based on their "gut" feelings rather than on logical analysis. In solving problems, they tend to rely more heavily on people for information rather than on their own technical analyses.

The diverger: learning by observing and feeling. People with this learning style are best at viewing concrete situations from many different points of view. Their approach to situations is to observe rather than take actions. They may enjoy situations that call for generating a wide range of ideas, such as brainstorming sessions. They probably have broad cultural interests and like to gather information.

The converger: learning by thinking and doing. People with this learning style are best at finding practical uses for ideas and theories. They have the ability to solve problems and make decisions based on finding solutions to questions. They would rather deal with technical tasks and problems than with social or interpersonal issues.

The assimilator: learning by observing and thinking. People with this learning style are best at understanding a wide range of information and putting it into a concise, logical form. They probably are less focused on people and more interested in abstract ideas and concepts. Generally, they will find it more important for a theory to have logical rather than practical value.

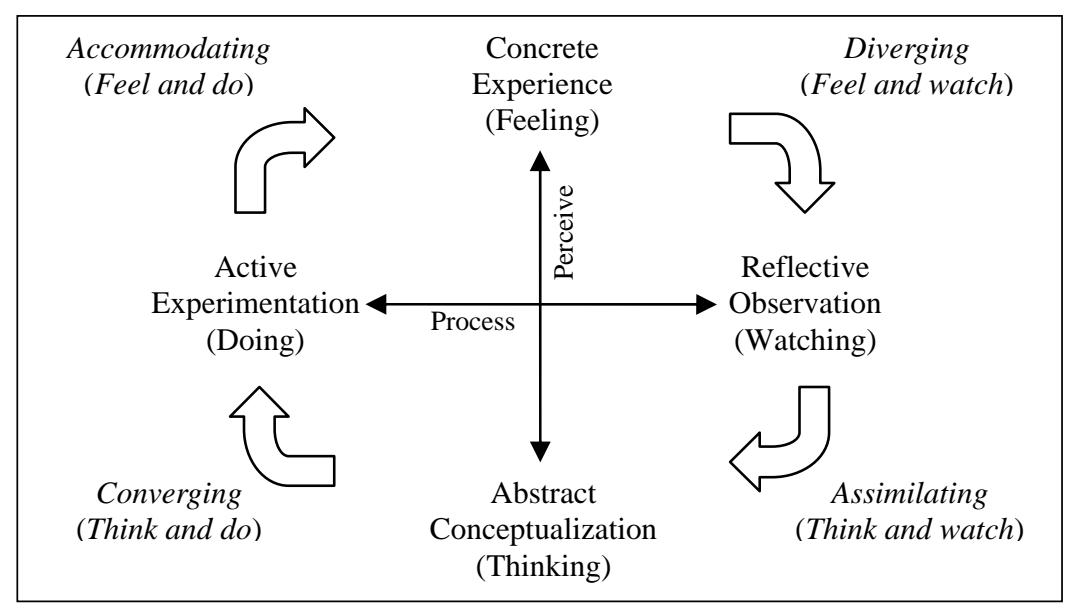

Figure 2. Kolb’s learning styles.

\section{Methodology}

\section{Population and Sample}

The number of visitors to the Phra Pathom Chedi National Museum is 953 per year (National Museum, 2013). The research sample in this study was undergraduate students who visit the Phra Pathom Chedi National Museum. Non-probability and purposive sampling was used until the number of participants that can represent a population (300 people) was attained by using the calibration table of Yamane (1973) with significance at the level of 0.05 , a size tolerance of \pm 5 , and a confidence level of $95 \%$. 


\section{Instruments}

A structured questionnaire was the only research instrument used. It consisted of three parts as follows:

(1) This part consisted of four items on the demographic information of the visitors, i.e., age, gender, educational level, and income;

(2) This part consisted of questions that explored the learning styles of the visitors. The items used to measure their learning styles involved close-ended questions and open-ended questions. The scoring was based on a 7-level rating evaluation scale according to the weight of the Osgood 7-level assessment (Osgood Scale, Osgood, Suci, \& Tannenbaum, 1957). This is the basis for the determination that is ordered from the highest score to the lowest score. There are 16 items in total;

(3) This section gives the visitors the opportunity to express their opinions and make suggestions related to their learning styles. It uses open-ended questions. The information from this section of the questionnaire allows the visitors to consider their thoughts about the strengths and weaknesses of learning when visiting the museum.

\section{Collection of Data}

The data collection for this study consisted of primary and secondary data from sources that met the objectives of the study as follows.

Primary data collection. The questionnaire handed out of the participants for collecting the data from the research sample (i.e., the tourists to the Phra Pathom Chedi National Museum).

Secondary data collection. In order to address the research objectives, the concepts and theories related to learning processes were used for analyzing those processes and the opportunities to develop them in the context of the visitors to the Phra Pathom Chedi National Museum. A collection of relevant documents, books, pamphlets, journals, theses, and related researches from both domestic and international sources, including data from online information resources from the public and private sectors, was used as a background for the empirical research.

\section{Data Analysis}

After collecting the data, the questionnaire was analyzed to verify the validity of the query. Subsequently, the data were statistically analyzed by computers. Descriptive statistics were used to describe the sample's variables quantitatively. The data were analyzed by calculating the statistics including the mean, standard deviation (SD), percentages, inferential statistics, and multiple regression analysis.

\section{Findings}

\section{Demographic Information}

The results of the analysis showed that most of the visitors to the museum were female. There were 190 female respondents (63.3\%) and 110 male respondents (36.7\%). The majority of the visitors were 19 years old (124 persons or $41.3 \%$ ), followed by those who were 18 years old, accounted for $40 \%$ of the visitors, and 40 persons who were 20 years old (13.3\%). It was found that the majority of respondents had studied at the undergraduate level (289 persons or 96.3\%) followed by those who had a high school education (11 people, representing 3.7\% of the total). The income levels of the participants were considerably less than 5,000 baht for 156 of the people (52\%), followed by those with an income of 5,001-10,000 baht (108 people or 36\%), and finally those with an income of 10,001-15,000 baht (29 persons or $9.7 \%$ of the total). 


\section{Analysis of the Learning Styles of the Museum Visitors}

The analysis of the data was done by categorizing the museum's visitors' learning styles according to four processes: (1) before learning; (2) when I have learning best; (3) while learning; and (4) the best ways of learning that create the most understanding. The descriptive statistics used included mean, SD, and comments.

Mean, SD, and comments: "before learning" process of museum visitors. Considered in a descending order, we found that the most frequent response was "I like learning by watching and listening", with a mean of 5.30 (SD = 1.386). This was followed by "I like learning by doing" with a mean of 5.14 (SD = 1.469), by "I prefer to learn by feeling" with a mean of 4.98 (SD = 1.484), and finally by "I am likely to have ideas while learning” with a mean of $4.77(\mathrm{SD}=1.330)$ (see Table 1$)$.

Table 1

Before Learning

\begin{tabular}{lllll}
\hline Before learning & $\bar{X}$ & SD & Placing & Descriptive rating (DR) \\
\hline I prefer to learn by feeling & 4.98 & 1.484 & 3 & Much \\
I like learning by watching and listening & 5.30 & 1.386 & 1 & Most \\
I am likely to have ideas while learning & 4.77 & 1.330 & 4 & Much \\
I like learning by doing & 5.14 & 1.469 & 2 & Much \\
Total & 5.040 & 1.126 & & Much \\
\hline
\end{tabular}

Mean, SD, and comments: "learning behavior" process of museum visitors. Considered in a descending order, we found that the most common response was "I am fully committed to success", with a mean of 5.36 ( $\mathrm{SD}=1.252$ ). This was followed by "I believe in intuition and feeling" with a mean of 4.74 $(\mathrm{SD}=1.506)$. The next highest response was "I fully listen and observe" with a mean of $4.71(\mathrm{SD}=1.299)$ and the lowest average response was "I trust in systematic thinking" with a mean of 4.68 (SD = 1.323) (see Table 2).

Table 2

Learning Behavior

\begin{tabular}{lllll}
\hline Learning behavior & $\bar{X}$ & SD & Placing & DR \\
\hline I believe in intuition and feeling & 4.74 & 1.506 & 2 & Much \\
I fully listen and observe & 4.71 & 1.299 & 3 & Much \\
I trust in systematic thinking & 4.68 & 1.323 & 4 & Much \\
I am fully committed to success & 5.36 & 1.252 & 1 & Most \\
Total & 4.870 & 1.052 & & Much \\
\hline
\end{tabular}

Mean, SD, and comments: "while learning” process of the museum visitors. Considered in a descending order, we found that the most common response was "I take responsibility for what I have learned" with a mean of 4.95 ( $\mathrm{SD}=1.277$ ), followed by "I have sense and react with strong feelings", with a mean of 4.81 (SD = 1.252). The next most common response was "I keep quiet and am reticent", with a mean of 4.72 (SD = 1.491) and the lowest was "I will always find reasons to support various learning methods", with a mean of $4.71(\mathrm{SD}=1.261)$ (see Table 3).

Mean, SD, and comments: "the best ways of learning that create the most understanding" process of the museum visitors. Considered in a descending order, here we found that the most common response was "learning by doing", with a mean of 5.37 (SD = 1.451), followed by "learning by thinking" with a mean of 5.03 (SD = 1.391). The next response was "learning by feeling" with a mean of 4.97 (SD = 1.447) and the least common was "learning by observing" with a mean of $4.09(\mathrm{SD}=1.316)$ (see Table 4). 
Table 3

While Learning

\begin{tabular}{lllll}
\hline While learning & $\bar{X}$ & SD & Placing & DR \\
\hline I have sense and react with strong feelings & 4.81 & 1.252 & 2 & Much \\
I keep quiet and am reticent & 4.72 & 1.491 & 3 & Much \\
I will always find reasons to support various learning methods & 4.71 & 1.261 & 4 & Much \\
I take responsibility for what I have learned & 4.95 & 1.277 & 1 & Most \\
Total & 4.797 & 1.033 & & Much \\
\hline
\end{tabular}

Table 4

The Best Ways of Learning That Create the Most Understanding

\begin{tabular}{lllll}
\hline The best ways of learning that create the most understanding & $\bar{X}$ & SD & Placing & DR \\
\hline Learning by feeling & 4.97 & 1.447 & 3 & Much \\
Learning by observing & 4.09 & 1.316 & 4 & Much \\
Learning by thinking & 5.03 & 1.391 & 2 & Much \\
Learning by doing & 5.37 & 1.451 & 1 & Most \\
Total & 5.087 & 1.167 & & Much \\
\hline
\end{tabular}

The key points of the results of this research have been discussed to conclude the settlement of all the facts, including the documents and related research and references. The results of the research found that the visitors to the Phra Pathom Chedi National Museum are mostly female and undergraduate students. This result is consistent with the findings of Hinton (1998) that most museum visitors will have a higher level of education and usually receive income from their families. Due to the changing population structure, this applies to the demographic group of undergraduate female students. Most of the visitors are young and usually visit the museum with their families or schools; therefore, they pay less for travelling.

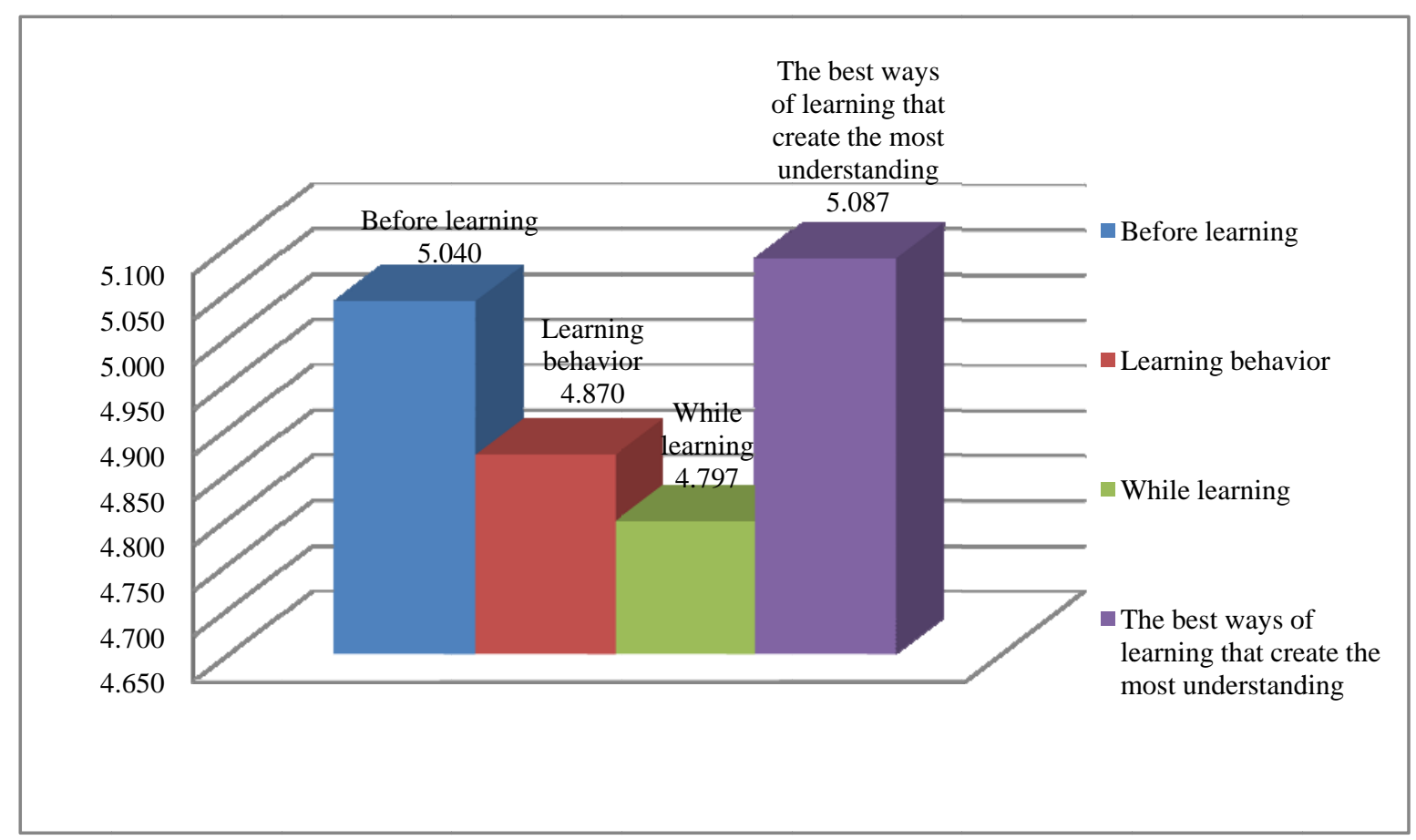

Figure 3. The mean score of each learning process. 
From Figure 3, visitors to the Phra Pathom Chedi National Museum have feelings for prior learning visit to the museum, and most prefer to learn by watching and listening. In addition, the learning behavior in the Phra Pathom Chedi National Museum is mostly in "action to be fully successful" and "while they are learning". Most of the learning is "while they are learning", which they have felt a responsibility to learn things. Most visitors have learning styles in "action that can create the most understanding". From this information, we can prioritize the learning styles of the visitors to the Phra Pathom Chedi National Museum which can be ranked in order of significance as follows: (1) the best ways of learning that create the most understanding; (2) before learning; (3) learning behavior; and (4) while learning.

Personal learning considering the independent variables of the multiple regression equation. After the multiple regression equation was estimated, the analysis of the independent variables in "Model (1) Accommodator: learning by doing and feeling” found that there were remaining independent variables in the equation. These can be described according to the level of learning in the first form with significance at the level of 3.831 when the hypothesis is tested at the significance level of 0.05 by the $F$-test (see Table 5).

Table 5

Model (1) Accommodator

\begin{tabular}{|c|c|c|c|c|c|c|}
\hline Model (1) & Source of variability & Sum of square & $\mathrm{df}$ & Mean square & $F$ & $P$-value \\
\hline \multirow{3}{*}{ Accommodator } & Regression & 36.138 & 8 & 4.517 & 3.831 & 0.000 \\
\hline & Residual & 343.169 & 291 & 1.179 & & \\
\hline & Total & 379.307 & 299 & & & \\
\hline
\end{tabular}

$R=0.309$

$R$ square $=0.095$

Adjusted $R$ square $=0.070$

Overall, all the independent variables could explain the self-learning styles at a significance level of around $7 \%$. All the independent variables are correlated in a linear manner with the multiple styles of learning at around $30.9 \%$ and can explain the variation of the acceptance level for the "accommodator" by around $9.5 \%$.

Table 6

The Multiple Regression Analysis of Model (1)

\begin{tabular}{|c|c|c|c|c|c|}
\hline \multirow{2}{*}{ Variable } & \multicolumn{2}{|c|}{ Unstandardized coefficient } & \multirow{2}{*}{$\begin{array}{l}\text { Standardized coefficient } \\
\text { Beta }\end{array}$} & \multirow{2}{*}{$T$} & \multirow{2}{*}{$P$-value } \\
\hline & $\mathrm{B}$ & Std. error & & & \\
\hline Constant & 7.654 & 1.581 & - & 4.840 & 0.000 \\
\hline Gender (sex) & 0.321 & 0.133 & 0.138 & 2.408 & 0.017 \\
\hline Age (age) & -0.171 & 0.076 & -0.129 & -2.251 & 0.025 \\
\hline Undergraduate education (ed) & 1.459 & 0.338 & 0.244 & 4.315 & 0.000 \\
\hline Income: $<5,000$ baht (sa1) & -0.936 & 0.639 & -0.416 & -1.464 & 0.144 \\
\hline Income: 5,001-10,000 baht (sa2) & -0.916 & 0.642 & -0.391 & -1.428 & 0.154 \\
\hline Income: $10,001-15,000$ baht (sa3) & -1.039 & 0.667 & -0.273 & -1.559 & 0.120 \\
\hline Income: $15,001-20,000$ baht (sa4) & -0.792 & 1.262 & -0.041 & -0.628 & 0.531 \\
\hline Income: 20,001-25,000 baht (sa5) & -1.287 & 0.893 & -0.114 & -1.440 & 0.151 \\
\hline
\end{tabular}

From the information in Table 6, the equation of the multiple linear regression of Model (1) is shown below: 


$$
\begin{gathered}
Y=7.65+0.32 \mathrm{sex}+(-0.17) \text { age }+1.46 e d+(-0.93) \mathrm{s} a 1+(-0.92) \mathrm{sa} 2 \\
(4.84)^{*}(2.41)^{*} \quad(-2.25)^{*} \quad(4.32)^{*} \quad(-1.46) \quad(-1.43) \\
+(-1.04) \mathrm{sa} 3+(-0.79) \mathrm{s} a 4+(-1.29) \mathrm{s} a 5+e \\
(-1.56) \quad(-0.63) \quad(-1.44)
\end{gathered}
$$

$R$ square $=0.095 \quad$ Adjusted $R$ square $=0.070$

It can be concluded that the factors that influence the learning styles of the "accommodator" are gender, age, and educational level. It was also found that the level of learning for the "accommodator" is higher when the visitor is young, male, and has an undergraduate level of education.

Table 7

Model (2) Diverger

\begin{tabular}{llcrlll}
\hline Model (2) & Source of variability & Sum of square & \multicolumn{1}{c}{ df } & Mean square & $F$ & $P$-value \\
\hline \multirow{3}{*}{ Diverger } & Regression & 33.548 & 8 & 4.194 & 4.102 & 0.000 \\
& Residual & 297.507 & 291 & 1.022 & & \\
& Total & 331.055 & 299 & & & \\
\hline
\end{tabular}

$R=0.308$

$R$ square $=0.101$

Adjusted $R$ square $=0.077$

After the multiple regression equation was estimated, the analysis of the independent variables in "Model (2) Diverger: learning by observing and feeling” found that there are remaining independent variables in the equation. These can describe the level of learning in the first form with significance at the level of 4.102 when the hypothesis is tested at the significance level of 0.05 by the F-test (see Table 7).

Overall, all the independent variables could explain the self-learning styles at a significance level of around $7.7 \%$. All the independent variables are correlated in a linear manner with the multiple styles of learning at around $30.8 \%$ and can explain the variation of the acceptance level for the "diverger" by around

\begin{tabular}{|c|c|c|c|c|c|}
\hline \multirow{2}{*}{ Variable } & \multicolumn{2}{|c|}{ Unstandardized coefficient } & \multirow{2}{*}{\multicolumn{2}{|c|}{$\begin{array}{l}\text { Standardized coefficient } \\
\text { Beta }\end{array}$}} & \multirow{2}{*}{$P$-value } \\
\hline & $\mathrm{B}$ & Std. error & & & \\
\hline Constant & 9.095 & 1.472 & & 6.177 & 0.000 \\
\hline Gender (sex) & -0.038 & 0.124 & -0.017 & -0.303 & 0.762 \\
\hline Age (age) & -0.233 & 0.071 & -0.188 & -3.304 & 0.001 \\
\hline Undergraduate education (ed) & 1.293 & 0.315 & 0.231 & 4.110 & 0.000 \\
\hline Income: < 5,000 baht (sa1) & -1.124 & 0.595 & -0.535 & -1.889 & 0.060 \\
\hline Income: 5,001-10,000 baht (sa2) & -1.050 & 0.597 & -0.480 & -1.757 & 0.080 \\
\hline Income: 10,001-15,000 baht (sa3) & -1.095 & 0.621 & -0.308 & -1.764 & 0.079 \\
\hline Income: 15,001-20,000 baht (sa4) & -2.193 & 1.175 & -0.120 & -1.866 & 0.063 \\
\hline Income: 20,001-25,000 baht (sa5) & -1.073 & 0.832 & -0.102 & -1.290 & 0.198 \\
\hline
\end{tabular}
$10.1 \%$.

Table 8

The Multiple Regression Analysis of Model (2)

From the information in Table 8, the equation of the multiple linear regression of Model (2) is shown below: 


$$
\begin{gathered}
Y=9.10+(-0.04) \mathrm{sex}+(-0.23) \text { age }+1.29 \mathrm{ed}+(-1.12) \mathrm{sa} 1+(-1.05) \mathrm{sa} 2 \\
(6.18)^{*}(-0.30) \quad(-3.30)^{*} \quad(4.11)^{*} \quad(-1.89) \\
+(-1.10) \mathrm{sa} 3+(-2.19) \mathrm{sa} 4+(-1.07) \mathrm{sa} 5+e \\
(-1.76) \quad(-1.87) \quad(-1.29)
\end{gathered}
$$

$R$ square $=0.101 \quad$ Adjusted $R$ square $=0.077$

These lead to the conclusion that the factors that influence the learning styles of the "diverger" are age and undergraduate level of education. It was also found that the level of learning for the diverger is higher when the visitor is young and has an undergraduate level of education.

Table 9

Model (3) Converger

\begin{tabular}{llcrlll}
\hline Model (3) & Source of variability & Sum of square & \multicolumn{1}{c}{ df } & Mean square & $F$ & $P$-value \\
\hline \multirow{4}{*}{ Converger } & Regression & 40.743 & 8 & 5.093 & 5.319 & 0.000 \\
& Residual & 278.642 & 291 & 0.958 & & \\
& Total & 319.385 & 299 & & & \\
\hline
\end{tabular}

$R=0.357$

$R$ square $=0.128$

Adjusted $R$ square $=0.104$

After the multiple regression equation was estimated, the analysis of the independent variables in "Model (3) Converger: learning by thinking and doing” found that there are remaining independent variables in the equation, which can describe the level of learning in the first form with the significance at the level of 5.319 (see Table 9). This was used to test the hypothesis at the level of 0.05 using the $F$-test.

Overall, all the independent variables could explain the self-learning styles at a significance of around $10.4 \%$. The independent variables are correlated in a linear manner with the multiple styles of learning at around $35.7 \%$ and can explain the variation of the acceptance level for the "converger" at about

\begin{tabular}{|c|c|c|c|c|c|}
\hline \multirow{2}{*}{ Variable } & \multicolumn{2}{|c|}{ Unstandardized coefficient } & \multirow{2}{*}{$\begin{array}{l}\text { Standardized coefficient } \\
\text { Beta }\end{array}$} & & \multirow{2}{*}{$P$-value } \\
\hline & $\mathrm{B}$ & Std. error & & & \\
\hline Constant & 8.681 & 1.425 & & 6.092 & 0.000 \\
\hline Gender (sex) & 0.134 & 0.120 & 0.063 & 1.117 & 0.265 \\
\hline Age (age) & -0.225 & 0.068 & -0.185 & -3.294 & 0.001 \\
\hline Undergraduate education (ed) & 1.466 & 0.305 & 0.267 & 4.814 & 0.000 \\
\hline Income: $<5,000$ baht (sa1) & -1.177 & 0.576 & -0.570 & -2.043 & 0.042 \\
\hline Income: 5,001-10,000 baht (sa2) & -1.064 & 0.578 & -0.495 & -1.840 & 0.067 \\
\hline Income: 10,001-15,000 baht (sa3) & -1.257 & 0.601 & -0.360 & -2.093 & 0.037 \\
\hline Income: 15,001-20,000 baht (sa4) & -1.599 & 1.137 & -0.089 & -1.406 & 0.161 \\
\hline Income: 20,001-25,000 baht (sa5) & -0.588 & 0.805 & -0.057 & -0.731 & 0.465 \\
\hline
\end{tabular}
$12.8 \%$.

Table 10

The Multiple Regression Analysis of Model (3)

From the information in Table 10, the equation of the multiple linear regression of Model (3) is shown below: 


$$
\begin{gathered}
Y=8.68+0.13 \mathrm{sex}+(-0.23) a g e+1.47 e d+(-1.18) \mathrm{sa} 1+(-1.06) \mathrm{sa} 2 \\
(6.09)^{*}(1.12) \quad(-3.29)^{*} \quad(4.81)^{*}(-2.04)^{*} \quad(-1.84) \\
+(-1.26) \mathrm{sa} a+(-1.60) \mathrm{sa} 4+(-0.59) \mathrm{sa} a+e \\
(-2.09)^{*} \quad(-1.41) \quad(-0.73)
\end{gathered}
$$

$R$ square $=0.128 \quad$ Adjusted $R$ square $=0.104$

From this equation, it can be concluded that the factors that influence the learning styles of the "converger" are age, an undergraduate level of education, an income of less than 5,000 baht, as well as an income of $10,000-15,000$ baht. It was found that the level of learning of the "converger" is higher when the visitor is young and has an undergraduate level of education with an income of more than 25,000 baht.

Table 11

Model (4) Assimilator

\begin{tabular}{lllrlll}
\hline Model (4) & Source of variability & Sum of square & \multicolumn{1}{l}{ df } & Mean square & $F$ & $P$-value \\
\hline \multirow{3}{*}{ Assimilator } & Regression & 50.164 & 8 & 6.270 & 5.104 & 0.000 \\
& Residual & 357.477 & 291 & 1.228 & & \\
& Total & 407.641 & 299 & & & \\
\hline
\end{tabular}

$R=0.351$

$R$ square $=0.123$

Adjusted $R$ square $=0.099$

After the multiple regression equation was estimated, the analysis of the independent variables in "Model (4) Assimilator: learning by observing and thinking” found that the remaining independent variables in the equation can describe the level of learning in the first form with significance at the level of 5.104 when the hypothesis is tested at the level of 0.05 by the $F$-test (see Table 11).

Overall, the independent variables which could explain the self-learning styles had a significance of around 9.9\%. The independent variables are correlated in a linear manner with the multiple styles of learning at around $35.1 \%$ and can explain the variation of the acceptance level for the "assimilator" at around

\begin{tabular}{|c|c|c|c|c|c|}
\hline \multirow{2}{*}{ Variable } & \multicolumn{2}{|c|}{ Unstandardized coefficient } & \multirow{2}{*}{\multicolumn{2}{|c|}{ Standardized coefficient }} & \multirow{2}{*}{$P$-value } \\
\hline & $\mathrm{B}$ & Std. error & Beta & & \\
\hline Constant & 9.376 & 1.614 & & 5.809 & 0.000 \\
\hline Gender (sex) & -0.026 & 0.136 & -0.011 & -0.189 & 0.851 \\
\hline Age (age) & -0.245 & 0.077 & -0.178 & -3.164 & 0.002 \\
\hline Undergraduate education (ed) & 1.718 & 0.345 & 0.277 & 4.979 & 0.000 \\
\hline Income: $<5,000$ baht (sa1) & -1.437 & 0.652 & -0.616 & -2.204 & 0.028 \\
\hline Income: 5,001-10,000 baht (sa2) & -1.278 & 0.655 & -0.526 & -1.951 & 0.052 \\
\hline Income: $10,001-15,000$ baht (sa3) & -1.188 & 0.680 & -0.301 & -1.747 & 0.082 \\
\hline Income: $15,001-20,000$ baht (sa4) & -2.189 & 1.288 & -0.108 & -1.699 & 0.090 \\
\hline Income: 20,001-25,000 baht (sa5) & -1.502 & 0.912 & -0.128 & -1.647 & 0.101 \\
\hline
\end{tabular}
$12.3 \%$.

Table 12

The Multiple Regression Analysis of Model (4)

From the information in Table 12, the equation of the multiple linear regression of Model (4) is shown below: 


$$
\begin{gathered}
Y=9.38+(-0.03) \mathrm{sex}+(-0.25) \mathrm{age}+1.72 \mathrm{ed}+(-1.44) \mathrm{sa} 1+(-1.28) \mathrm{sa} 2 \\
(5.81)^{*}(-0.19) \quad(-3.16)^{*} \quad(4.98)^{*}(-2.20)^{*} \quad(-1.95) \\
+(-1.19) \mathrm{sa} 3+(-2.19) \mathrm{sa} 4+(-1.50) \mathrm{sa} 5+e \\
(-1.75) \quad(-1.70) \quad(-1.65)
\end{gathered}
$$

$R$ square $=0.123 \quad$ Adjusted $R$ square $=0.099$

From the equation above, it can be concluded that the factors that influence the learning styles of the "assimilator" are age, an undergraduate education level, and an income of below 5,000 baht. It was also found that the level of learning of the "assimilator" is higher when the visitor is young and has an undergraduate level of education and an income of over 25,000 baht.

\section{Discussion and Conclusion}

The conclusion of this study is that most of the visitors to the Phra Pathom Chedi National Museum are female and have an undergraduate level of education. This is in line with the research of Hinton (1998), which found that the majority of museum visitors are highly educated and receive income from their families. This can be attributed to changes in the population structure, which has resulted in an increase of young females. It follows then that most of the visitors are young and usually come to the museum accompanied by their families or with the schools, which means that they spend less during their visits. This study tries to gain an accurate understanding of museum visitors, especially students, who are considered to be the group with the highest potential for using their knowledge for the development of the country in the future. In addition, the results of this study could be applied to other museums in Thailand as a guideline for attracting more visitors and developing programs that further the learning of museum visitors.

\section{References}

Hinton, M. (1998). The Victoria and Albert Museum silver galleries II: Learning style and interpretation preference in the discovery area. Museum Management and Curatorship, 17(3), 253-294.

Kolb, D. (1984). Experiential learning: Experience as the source of learning and development. Englewood Cliffs, New Jersey, NJ: Prentice-Hall.

Kolb, D. (1985). LSI learning-style inventory. Boston: McBer \& Company, Traning Resources Group.

National Museum. (2013). National museum statstics. Office of Archaeology and National Museum, Fune Arts Department. Bangkok: Thailand.

Osgood, C. E., Suci, G., \& Tannenbaum, P. (1957). The measurement of meaning. Urbana, IL: University of Illiois Press.

Pavlov, I. P. (1927). Conditioned reflexese: An investigation of the physiological activitiy of the cerebral cortex. London: Oxford University Press.

Skinner, B. F. (1938). The behavior of organisms: An experimental analysis. Oxford, England: Appleton-Century.

Yamane, T. (1973). Satatistics: An introductory analysis (3rd ed.). New York, NY: Harper and Row Publication. 